\title{
PENGEMBANGAN MEDIA PEMBELAJARAN KOMIK FISIKA DIGITAL BERBASIS LINE WEBTOON PADA POKOK BAHASAN TEKANAN
}

\author{
Diah Setiani, Putri Fathiya Artha Dewi, Savithri Maurizki Delya,Vera Rahmawati, \\ Dasmo \\ Program Studi Pendidikan Fisika, Universitas Indraprasta PGRI \\ Email: diyahsetiani.19@gmail.com
}

Diterima: 17 Juli 2021. Direvisi: 18 Agustus 2021. Disetujui: 30 September 2021

\begin{abstract}
Abstrak
Penelitian ini didasarkan pada kurang tersedianya media pembelajaran yang dapat meningkatkan minat dan motivasi belajar fisika siswa. Penelitian ini bertujuan untuk menghasilkan media pembelajaran komik fisika digital berbasis line webtoon dengan pokok bahasan tekanan. Penelitian ini merupakan penelitian pengembangan dengan mengacu pada model 4D (Define, Design, Develop, dan Disseminate). Metode pengumpulan data yang digunakan adalah angket melalui Google Form. Instrumen penelitian yang digunakan meliputi angket kebutuhan peserta didik, angket validasi ahli, dan angket respon peserta didik. Jenis data yang digunakan terdiri dari data kuantitatif dan data kualitatif. Penelitian ini memperoleh hasil penilaian validasi dengan nilai persentase rata-rata sebesar $93,81 \%$. Hasil respon peserta didik memperoleh hasil penilaian dengan nilai rata-rata indikator sebesar 3,82 dan nilai persentase rata-rata sebesar 95,50\%. Berdasarkan keseluruhan hasil penelitian dan pembahasan disimpulkan bahwa komik fisika digital berbasis line webtoon sudah layak untuk digunakan dalam pembelajaran fisika.
\end{abstract}

Kata Kunci: Media Pembelajaran, Komik Digital, Line Webtoon, Fisika, Tekanan.

\begin{abstract}
This research is based on the lack of availability of learning media that can increase students' interest and motivation in learning physics. This study aims to produce learning media for digital physics comics based on line webtoon with the subjects of pressure. This research is a Research \& Development with 4D (Define, Design, Develop and Disseminate) models. The data collection method used is a questionnaire, an expert validation questionnaire, and student response questionnaire. The types of data used include quantitative data and qualitative data. This study obtained the results of the validation assessment with an average indicator value of 93,81\%. The results of the student responses obtained the results of the assessment with an average indicator value of 3,82 and an average percentage value of $95,50 \%$. Based on the overall results of the research and discussion, it is concluded that digital physics comics based on line webtoon are feasible to be used in physics learning.
\end{abstract}

Keywords: Learning Media, Digital Comic, Line Webtoon, Physics, Pressure. 
Setiani., Dewi., Delya., Rahmawati., Dasmo - Pengembangan Media ...

\section{PENDAHULUAN}

IPA (Fisika) merupakan ilmu sains yang memiliki peranan penting dalam berkontribusi sebagai pengembangan IPTEK. IPA (Fisika) merupakan pembelajaran yang membutuhkan daya berpikir, daya bernalar, daya beranalisis, dan sikap ilmiah untuk memahami konsep sebagai pemecahan masalah dalam kehidupan sekitarnya.

Ruang lingkup dari IPA (Fisika) berawal dari masalah yang terjadi di lingkungan sekitar peserta didik hingga lingkungan terjauh yaitu lingkungan masyarakat sehingga pembelajaran IPA (Fisika) bertujuan untuk mengembangkan kemampuan peserta didik dalam memahami setiap peristiwa alam baik yang muncul secara alamiah maupun buatan campur tangan manusia dan memahami konsep sebagai penyelesaian masalah IPA (Fisika) yang terjadi dalam kehidupan seharihari. Namun, pentingnya peranan IPA (Fisika) tidak sebanding dengan minat dan motivasi sehingga banyak peserta didik yang tidak mampu memahami materi IPA (fisika).
Berdasarkan hasil angket analisis kebutuhan peserta didik yang telah dilakukan sebanyak 50 peserta didik kelas 8 di SMP Jawa Tengah diperoleh data bahwa sebanyak 80\% peserta didik masih menggunakan buku IPA (Fisika). Namun, buku IPA (Fisika) yang dimiliki oleh peserta didik bercetak tebal dan hanya berisiteks narasi yang sangat panjang sehingga mengurangi minat siswa yang dimana sekitar $76 \%$ peserta didik menyatakan bahwa belajar dengan menggunakan buku cetak IPA (Fisika) masih sulit dipahami dan $70 \%$ peserta didik kurang tertarik dengan buku IPA (Fisika) karena kurang minat dan memotivasi belajar, kurang menarik, dan tidak dapat memahami penjelasan materi.

Dalam memahami konsep fisika diperlukan penggambaran dan analisis. Konsep-konsep fisika yang harus dihubungkan dengan kehidupan sehari-hari menjadikan materi fisika sangat penting untuk dipelajari. Gambar merupakan bentuk visual untuk memudahkan peserta didik dalam memahami konsep fisika. Salah satu syarat gambar untuk menerapkan konsep fisika dan dapat 
Setiani., Dewi., Delya., Rahmawati., Dasmo - Pengembangan Media ...

digunakan sebagai media pembelajaran adalah komik.

Komik adalah media perantara yang terdiri dari ide-ide fiksi dan nonfiksi yang disampaikan melalui gambar visual untuk menjelaskan jalannya sebuah cerita melalui alur cerita. Komik memberikan kekuatan yang luar biasa dalam menyampaikan pesan dan kontribusi dalam memotivasi peserta didik untuk aktif karena kalimat yang digunakan oleh komik bersifat sederhana sehingga memudahkan peserta didik untuk memahami suatu konsep (Ntobuono, Arbie, \& Amali, 2018); (Sari, Ratnaningtyas, Wilujeng, \& Kuswanto, 2019).

Seiring dengan perkembangan TIK yang semakin maju, maka komik konvensional dapat bertransformasi menjadi komik digital. Komik digital merupakan salah satu bentuk pengembangan teknologi media pembelajaran fisika yang dapat diakses bagi pengguna smartphone.

Komik digital dapat digunakan sebagai bahan ajar mandiri, memberikan arahan yang jelas terkait proses pembelajaran, meningkatkan minat siswa, memahami materi, dan meningkatkan kemampuan mengingat peserta didik (Priyadi \& Kuswanto, 2020).

Hasil penelitian sebelumnya yang telah dilakukan oleh (Muliyati, et al., 2021) memperoleh hasil validasi penilaian oleh ahli materi sebesar $78 \%$, ahli desain grafis sebesar $87 \%$, dan ahli bahasa sebesar $80 \%$ dan diperoleh kesimpulan bahwa komik digital fisika dapat digunakan sebagai media pembelajaran fisika dan penyampaian pesan pembelajaran dapat diintegrasikan melalui kombinasi visual dan cerita dalam produk komik tersebut. Hasil penelitian ini sejalan dengan riset yang menyatakan bahwa penggunaan komik digital yang memiliki ilustrasi warna yang menarik mampu membantu peserta didik belajar lebih banyak dan memahami materi fisika karena memvisualisasikan hal yang rumit menjadi lebih sederhana dengan cerita yang kuat (Fauziah \& Kuswanto, 2021).

Penggunaan media pembelajaran perlu melibatkan sesuatu yang lebih akrab dengan peserta didik. Media pembelajaran merupakan alat bantu sebagai perantara antara guru dan 
Setiani., Dewi., Delya., Rahmawati., Dasmo - Pengembangan Media ...

peserta didik yang digunakan untuk menyampaikan materi pembelajaran agar mampu menumbuhkan minat dan daya tarik belajar peserta didik, meminimalisir sikap pasif peserta didik, dan menstimulus peserta didik untuk lebih konsentrasi dalam belajar agar lebih efektif dan efisien (Siswoyo, Muliyati, Rahmadini, Purwahida, \& Simanjuntak, 2021).

Salah satu aplikasi yang lebih akrab oleh peserta didik dan dapat digunakan sebagai inovasi media pembelajaran adalah Line Webtoon. Media pembelajaran dengan menggunakan komik Webtoon dapat memotivasi belajar siswa dalam mencari sumber belajar secara mandiri dan meningkatkan minat literasi peserta didik (Hidayat, Rostikawati, \& Marris, 2019).

Kelebihan Line Webtoon adalah kemudahan mengakses dengan mengunduh aplikasi secara gratis, dapat digunakan setiap saat sehingga memiliki nilai efektifitas dan nilai guna, dan memiliki banyak pengguna sehingga dapat dijangkau pembaca lebih luas termasuk kalangan peserta didik. Atas dasar itu, perlu dilakukan pengembangkan komik fisika digital berbasis line webtoon sebagai media pembelajaran.

\section{METODE}

Penelitian ini merupakan penelitian pengembangan (Research \& Development) dengan model 4D yaitu Define (Pendefinisian), Design (Perencanaan), Develop (Pengembangan), dan Disseminate (Penyebaran). Tahap Define (Pendefinisian) dilakukan dengan menganalisis masalah sesuai kebutuhan peserta didik dan menganalisis pemilihan materi yang berkaitan dengan tekanan. Tahap Design (Perencanaan) dilakukan dengan menetapkan Kompetensi Dasar (KD) dan indikator pembelajaran yang berkaitan dengan materi tekanan, membuat storyline dan naskah komik (script), mendesain komik (karakter dan latar). Tahap Develop (Pengembangan) dilakukan dengan membuat sketsa berbantuan software Ibis Paint $\mathrm{X}$ yang menghasilkan output berupa gambar berformat PNG dan membuat instrument penelitian. Setelah komik selesai dibuat, komik divalidasi oleh ahli materi, ahli media, dan ahli 
Setiani., Dewi., Delya., Rahmawati., Dasmo - Pengembangan Media ...

bahasa melalui angket validasi ahli secara online melalui Google Form.

Tahap Disseminate (Penyebaran) dilakukan dengan mengupload komik ke line webtoon dan komik diberikan penilaian oleh peserta didik melalui angket respon peserta didik secara online melalui Google Form.

Instrumen penelitian yang digunakan adalah angket kebutuhan peserta didik, angket validasi ahli, dan angket respon peserta didik dengan menggunakan skala likert. Angket kebutuhan peserta didik bertujuan untuk menganalisis kebutuhan peserta didik. Angket validasi ahli bertujuan untuk mengetahui kelayakan produk yang diperoleh melalui penilaian uji validasi ahli materi, ahli media, dan ahli bahasa. Angket respon peserta didik bertujuan untuk mengetahui kelayakan produk melalui respon peserta didik

Jenis data yang terkumpul pada proses pengembangan produk ini terdiri dari data kuantitatif dan data kualitatif. Data kuantitatif diperoleh dari hasil pengisian angket validasi ahli dan angket respon peserta didik untuk menilai kelayakan komik fisika digital. Data kualitatif diperoleh dari masukan, saran, kritik, dan tanggapan berkaitan tentang produk komik fisika digital yang dikembangkan. Penentuan skor Skala Likert dilakukan secara apriori dengan kategori penilaian yang disediakan untuk instrumen uji validitas pada Tabel 1.

Tabel 1. Kategori Penilaian Skor Skala Likert

\begin{tabular}{ccc}
\hline No & Nilai & Klasifikasi \\
\hline 1 & 4 & Sangat Baik \\
2 & 3 & Baik \\
3 & 2 & Kurang Baik \\
4 & 1 & Tidak Baik \\
\hline
\end{tabular}

Teknik analisis data yang teknik analisis persentase nilai ratadigunakan untuk menganalisis data rata ini menggunakan rumus dari hasil validasi adalah perhitungan Sudijono (Dasmo, Astuti, \& persentase nilai rata-rata. Penentuan Nurullaeli, 2017) sebagai berikut: 
Setiani., Dewi., Delya., Rahmawati., Dasmo - Pengembangan Media ...

$$
P=\frac{f}{N} x 100 \%
$$

Keterangan:

$P \quad:$ Angka persentase

$f \quad$ : Frekuensi yang diperoleh

$N \quad$ : Jumlah banyaknya individu

Untuk mengubah persentase nilai rata-rata yang diperoleh ke dalam bentuk kualitatif dapat dilihat pada Tabel 2. Sementara itu, analisis data respon peserta didik serupa dengan kriteria kelayakan produk. Persentase nilai rata-rata dari angket respon selanjutnya diubah ke dalam bentuk kualitatif berdasarkan Tabel 3.

Tabel 2.Kriteria Kelayakan Produk

\begin{tabular}{ccc}
\hline No & Skor Angket & Klasifikasi \\
\hline 1 & $80 \%<$ skor $<100 \%$ & Sangat Baik \\
2 & $60 \%<$ skor $<79,99 \%$ & Baik \\
3 & $50 \%<$ skor $<59,99 \%$ & Kurang Baik \\
4 & $0 \%<$ skor $<49,99 \%$ & Tidak Baik \\
\hline
\end{tabular}

Sumber: (Astuti, Sumarni, \& Saraswati, 2017)

Tabel 3.Kriteria Kategori Respon Peserta Didik

\begin{tabular}{ccc}
\hline No & Skor Angket & Klasifikasi \\
\hline 1 & $80 \%<$ skor $<100 \%$ & Sangat Baik \\
2 & $60 \%<$ skor $<79,99 \%$ & Baik \\
3 & $50 \%<$ skor $<59,99 \%$ & Kurang Baik \\
4 & $0 \%<$ skor $<49,99 \%$ & Tidak Baik \\
\hline
\end{tabular}

Sumber: (Astuti, Sumarni, \& Saraswati, 2017)

\section{HASIL DAN PEMBAHASAN}

\section{Hasil Penelitian}

Pada tahap Define, berdasarkan hasil analisis kebutuhan peserta didik diperoleh informasi bahwa peserta didik masih menggunakan buku cetak berhalaman tebal sehingga mengurangi minat dan motivasi belajar sehingga peserta didik masih kesulitan untuk memahami pokok bahasan tekanan.

Berdasarkan hasil analisis pemilihan materi diperoleh $\mathrm{KD} 3.8$ yaitu memahami tekanan zat cair dan penerapannya dalam kehidupan sehari-hari dan indikator 
Setiani., Dewi., Delya., Rahmawati., Dasmo - Pengembangan Media ...

pembelajaran yaitu: (1) peserta didik mampu memahami tentang tekanan, tekanan hidrostatis, hukum pascal, dan hukum archimedes; (2) peserta didik mampu memahami faktor-faktor dalam tekanan, tekanan hidrostatis, hukum pascal, dan hukum archimedes; (3) peserta didik mampu menghitung besar tekanan, tekanan hidrostatis, hukum pascal, dan hukum archimedes; (4) peserta didik mampu mengaplikasikannya konsep tekanan, tekanan hidrostatis, hukum archimedes, dan hukum pascal dalam kehidupan sehari-hari.

Setelah memperoleh informasi dari tahap Define, selanjutnya dilakukan Design dengan menetapkan indikator pembelajaran yang sesuai dengan Kompetensi Dasar (KD) pokok bahasan tekanan tingkat SMP, membuat storyline dan naskah komik (script) dan mendesain komik (karakter dan latar).

Tahap selanjutnya adalah Develop dengan membuat sketsa sebagai visualisasi berbantuan software Ibis Paint $\mathrm{X}$ dan membuat instrument penelitian untuk validator ahli dan responden peserta didik. Setelah komik selesai dibuat, komik dilakukan pengujian validasi oleh ahli materi, ahli media, dan ahli bahasa melalui angket validasi ahli secara online melalui Google Form. Alat dan bahan yang digunakan dalam mendesain dan membuat komik adalah Software Ibis Paint $\mathrm{X}$, Microsoft Word 2010, laptop, tablet, dan smartphone.

Uji ahli materi, ahli media, dan ahli bahasa dilakukan pada validator yang ahli di bidangnya meliputi dua orang guru mata pelajaran IPA sebagai validator ahli materi, dua orang guru mata pelajaran Fisika sebagai validator ahli media, dan dua orang guru mata pelajaran Bahasa Indonesia sebagai validator ahli bahasa.

\section{Validasi Ahli Materi}

Ahli materi merupakan validator yang dipilih untuk menilai aspek materi, aspek kebahasaan, dan aspek tampilan. Pada tahap uji kelayakan materi dilakukan oleh dua guru mata pelajaran IPA untuk melakukan pengisian angket uji validasi melalui Google Form. Dari hasil analisis angket validasi ahli materi didapatkan hasil penilaian pada Tabel 4. 
Setiani., Dewi., Delya., Rahmawati., Dasmo - Pengembangan Media ...

Tabel 4.Hasil Analisis Validasi Ahli Materi

\begin{tabular}{ccccc}
\hline No & Indikator & Nilai Indikator & $\begin{array}{c}\text { Nilai Persentase } \\
(\mathbf{\%})\end{array}$ & Klasifikasi \\
\hline 1 & Aspek Materi & 3,81 & $95 \%$ & Sangat Baik \\
2 & Aspek Kebahasaan & 3,78 & $94,5 \%$ & Sangat Baik \\
3 & $\begin{array}{c}\text { Aspek Gambar dan } \\
\text { Visual }\end{array}$ & 3,80 & $95 \%$ & Sangat Baik \\
& Rata-rata & 3,79 & $94,83 \%$ & Sangat Baik \\
& & & & \\
\hline
\end{tabular}

Berdasarkan hasil penilaian yang telah dilakukan oleh dua validator ahli materi pada tabel 4 diperoleh nilai rata-rata keseluruhan aspek pada nilai indikator sebesar 3,79 dan nilai persentase sebesar $94,83 \%$ yang menunjukkan bahwa komik fisika digital termasuk dalam klasifikasi sangat baik, maka komik fisika digital berbasis line webtoon layak digunakan sebagai media pembelajaran. Namun, ada beberapa masukan yang peneliti jadikan sebagai bahan revisi.

\section{Validasi Ahli Media}

Ahli media merupakan validator yang dipilih untuk menilai aspek gambar dan visual, aspek tulisan, aspek kebahasaan dan aspek penggunaan. Pada tahap uji kelayakan media dilakukan oleh dua guru mata pelajaran fisika untuk melakukan pengisian angket uji validasi melalui Google Form. Dari hasil analisis angket validasi ahli media didapatkan hasil penilaian pada Tabel 5 .

Berdasarkan tabel 5 hasil analisis angket validasi ahli media tentang produk komik fisika digital yang dikembangkan memperoleh hasil penilaian aspek gambar dan visual untuk nilai indikator sebesar 3,70 dan nilai persentase sebesar 92,50\% sehingga memperoleh klasifikasi sangat baik, untuk aspek tulisan memperoleh nilai indikator 3,62 dan nilai persentase $90,62 \%$ sehingga memperoleh klasifikasi sangat baik, untuk aspek gambar dan visual memperoleh nilai indikator 3,87 dan nilai persentase $96,87 \%$ sehingga memperoleh klasifikasi sangat baik, untuk aspek penggunaan memperoleh nilai skor indikator 4,00 dan nilai 
Setiani., Dewi., Delya., Rahmawati., Dasmo - Pengembangan Media ...

persentase $\quad 100 \%$ sehingga dialog percakapan, dan penggunaan memperoleh klasifikasi sangat baik. ukuran balon kata. Namun, ada Saran dan masukan yang sudah beberapa masukan yang peneliti diperbaiki diantaranya yaitu jadikan sebagai bahan revisi. penentuan visualisasi gambar, isi

Tabel 5.Hasil Analisis Validasi Ahli Media

\begin{tabular}{ccccc}
\hline No & Indikator & Nilai Indikator & $\begin{array}{c}\text { Nilai Persentase } \\
(\boldsymbol{\%})\end{array}$ & Klasifikasi \\
\hline 1 & $\begin{array}{c}\text { Aspek Gambar dan } \\
\text { Visual }\end{array}$ & 3,70 & $92,50 \%$ & Sangat Baik \\
& Aspek Tulisan & 3,62 & $90,62 \%$ & Sangat Baik \\
3 & Aspek Bahasa & 3,87 & $96,87 \%$ & Sangat Baik \\
4 & Aspek Penggunaan & 4,00 & $100 \%$ & Sangat Baik \\
& Rata-rata & 3,79 & $94,99 \%$ & Sangat Baik \\
\hline
\end{tabular}

3. Validasi Ahli Bahasa

Ahli bahasa merupakan validator yang dipilih untuk menilai aspek tulisan, aspek lugas, aspek komunikatif, aspek kesesuaian dengan perkembangan peserta didik, dan aspek kesesuaian dengan kaidah bahasa. Pada tahap uji kelayakan bahasa dilakukan oleh dua guru mata pelajaran Bahasa Indonesia untuk melakukan pengisian angket uji validasi melalui Google Form. Dari hasil analisis angket validasi ahli bahasa didapatkan hasil penilaian seperti Tabel 6.
Berdasarkan tabel 6 hasil analisis angket validasi ahli bahasa tentang produk komik fisika digital yang dikembangkan memperoleh hasil penilaian aspek tulisan untuk nilai indikator sebesar 3,87 dan nilai persentase $\quad 96,87 \% \quad$ sehingga memperoleh klasifikasi sangat baik, untuk aspek lugas memperoleh nilai indikator 3,50 dan nilai persentase $87,50 \%$ sehingga memperoleh klasifikasi sangat baik, untuk aspek komunikatif memperoleh nilai indikator 3,50 dan nilai persentase $87,50 \%$ sehingga memperoleh klasifikasi sangat baik, untuk aspek 
Setiani., Dewi., Delya., Rahmawati., Dasmo - Pengembangan Media ...

kesesuaian dengan perkembangan memperoleh klasifikasi sangat baik. peserta didik memperoleh nilai Saran dan masukan yang sudah indikator 3,75 dan nilai persentase diperbaiki diantaranya yaitu 93,75\% sehingga memperoleh menentukan struktur kalimat pada isi klasifikasi sangat baik, untuk aspek dialog dan penggunaan ejaan pada kesesuaian dengan kaidah bahasa dialog percakapan. Namun, ada memperoleh nilai indikator 3,70 dan beberapa masukan yang peneliti nilai persentase $92,50 \%$ sehingga jadikan sebagai bahan revisi.

Tabel 6. Hasil Analisis Validasi Ahli Bahasa

\begin{tabular}{|c|c|c|c|c|}
\hline No & Indikator & $\begin{array}{c}\text { Nilai } \\
\text { Indikator }\end{array}$ & $\begin{array}{c}\text { Nilai Persentase } \\
(\%)\end{array}$ & Klasifikasi \\
\hline 1 & Aspek Tulisan & 3,87 & $96,87 \%$ & Sangat Baik \\
\hline 2 & Aspek Lugas & 3,50 & $87,50 \%$ & Sangat Baik \\
\hline 3 & Aspek Komunikatif & 3,50 & $87,50 \%$ & Sangat Baik \\
\hline 4 & $\begin{array}{c}\text { Aspek Kesesuaian } \\
\text { dengan Perkembangan } \\
\text { Peserta Didik }\end{array}$ & 3,75 & $93,75 \%$ & Sangat Baik \\
\hline 5 & $\begin{array}{c}\text { Aspek Kesesuaian } \\
\text { dengan Kaidah Bahasa }\end{array}$ & 3,70 & $92,50 \%$ & Sangat Baik \\
\hline & Rata-rata & 3,66 & $91,62 \%$ & Sangat Baik \\
\hline
\end{tabular}

4. Responden Peserta Didik

Hasil penelitian dan pengembangan berupa komik fisika digital berbasis line webtoon diujicobakan pada peserta didik sebanyak lima puluh responden peserta didik kelas VIII SMP Se-Jawa Tengah secara acak untuk memberikan penilaian terhadap produk komik fisika digital berbasis line webtoon. Dari hasil analisis angket respon peserta didik didapatkan hasil penilaian seperti Tabel 7.

Berdasarkan hasil penilaian yang telah diperoleh dari lima puluh peserta didik menunjukkan bahwa nilai rata-rata keseluruhan aspek pada nilai indikator sebesar 3,82 dan nilai persentase sebesar $95,50 \%$ yang menunjukkan bahwa komik fisika digital termasuk dalam klasifikasi 
Setiani., Dewi., Delya., Rahmawati., Dasmo - Pengembangan Media ...

sangat baik. Hal ini menunjukkan digunakan sebagai media bahwa media komik fisika digital pembelajaran.

berbasis line webtoon layak untuk

Tabel 7. Hasil Angket Respon Peserta Didik

\begin{tabular}{ccccc}
\hline No & Indikator & Nilai Indikator & $\begin{array}{c}\text { Nilai Persentase } \\
(\%)\end{array}$ & Klasifikasi \\
\hline 1 & Aspek Materi & 3,86 & $96,50 \%$ & Sangat Baik \\
2 & Aspek Tulisan & 3,76 & $94 \%$ & Sangat Baik \\
3 & $\begin{array}{c}\text { Aspek Gambar dan } \\
\text { Visual }\end{array}$ & 3,84 & $96 \%$ & Sangat Baik \\
& Rata-rata & 3,82 & $95,50 \%$ & Sangat Baik \\
& & & & \\
\hline
\end{tabular}

\section{Pembahasan Penelitian}

Tujuan utama dari penelitian ini adalah untuk mengembangkan produk komik fisika digital berbasis line webtoon dan mengetahui kelayakan media pembelajaran komik fisika digital berbasis line webtoon sebagai pembelajaran fisika.

Penentuan media pembelajaran memiliki peranan yang sangat penting untuk menentukan proses pembelajaran yang efektif dan efisien, baik di kelas maupun di rumah. Media pembelajaran menjadikan sebuah inovasi yang harus dikuasai guru untuk menunjang proses pembelajaran agar materi yang disampaikan guru pada proses pembelajaran dapat diterima oleh peserta didik dengan baik. Hal ini selaras dengan pernyataan (Saputra, Pasha, \& Afriska, 2020) mengemukakan bahwa media pembelajaran yang dirancang dengan menggunakan software akan lebih mudah digunakan oleh guru dalam proses pembelajaran.

Komik fisika digital merupakan salah satu bentuk media visual yang menggabungkan narasi, gambar, dan warna yang dikemas sedemikian rupa sehingga membentuk sebuah cerita dengan memanfaatkan perangkat smartphone berbasis line webtoon agar peserta didik mampu memahami konsep fisika melalui penggabungan antara konsep fisika melalui penyampaian komunikasi visual 
Setiani., Dewi., Delya., Rahmawati., Dasmo - Pengembangan Media ...

dengan kehidupan sehari-hari sebagai jembatan penghubung pesan, peserta didik mampu mengembangkan dan menghasilkan ide yang lebih terarah, dan peserta didik mampu mengembangkan keterampilan berpikir kritis, berpikir analitis dan melibatkan rasa emosionalnya sehingga komik ini memiliki banyak manfaat yang dapat mengembangkan keterampilan kognitif, afektif dan psikomotor peserta didik (Ramadhan, Ratnaningtyas, Kuswanto, \& Wardani, 2019); (Zaibon, Azman, \& Shiratuddin, 2019); (Lamminpää, Vesterinen, \& Puutio, 2020).

\section{KESIMPULAN DAN SARAN}

\section{Kesimpulan}

Berdasarkan hasil penelitian dapat disimpulkan bahwa:

1. Penelitian pengembangan komik fisika digital berbasis line webtoon ini menggunakan langkah-langkah pengembangan model 4D yaitu Define (Pendefinisian), Design (Perencanaan), Develop (Pengembangan), dan Disseminate (Penyebaran).

2. Dari hasil penelitian yang telah dilakukan melalui hasil analisis angket validasi dari 6 validator ahli yang terdiri atas 2 validator ahli materi, 2 validator ahli media, dan 2 validator ahli bahasa memperoleh hasil penilaian bahwa nilai rata-rata indikator sebesar 3,74 dan persentase 93,81\% dengan klasifikasi sangat baik atau sangat layak. Hal ini menunjukkan bahwa media komik fisika digital berbasis line webtoon layak untuk digunakan sebagai media pembelajaran.

3. Dari hasil penelitian yang telah dilakukan melalui hasil analisis angket respon peserta didik diperoleh nilai rata-rata indikator sebesar 3,82 dan persentase sebesar $95,50 \%$. Hal ini menunjukkan bahwa media komik fisika digital berbasis line webtoon layak untuk digunakan sebagai media pembelajaran.

\section{Saran}

Berdasarkan hasil penelitian dan pembahasan, maka terdapat beberapa saran sebagai berikut:

1. Penelitian ini dilakukan hanya sebatas pada pengujian kelayakannya yang dilakukan oleh ahli materi, ahli media, ahli bahasa, dan peserta didik. Oleh karena itu, peneliti mengharapkan agar penelitian 
Setiani., Dewi., Delya., Rahmawati., Dasmo - Pengembangan Media ...

selanjutnya melakukan uji coba lapangan kepada guru dan peserta didik untuk mengetahui nilai keefektifan dan kepraktisan penggunaan komik fisika digital.

2. Media pembelajaran komik fisika digital berbasis line webtoon ini sebaiknya dikembangkan lagi pada materi-materi IPA (fisika) lainnya.

3. Komik yang peneliti sajikan dalam bentuk online sehingga membutuhkan akses jaringan internet, peneliti selanjutnya dapat membuat aplikasi komik fisika agar tersedia secara offline.

\section{DAFTAR PUSTAKA}

Astuti, I. A., Sumarni, R. A., \& Saraswati, D. L. (2017). Pengembangan Media Pembelajaran Fisika Mobile Learning Berbasis Android. Jurnal Penelitian dan Pengembangan Pendidikan Fisika (JPPF), 3 (1), 57-62.

Dasmo, D., Astuti, I. A., \& Nurullaeli, N. (2017). Pengembangan Pocket Mobile Learning Berbasis Android. Jurnal Riset dan Kajian Pendidikan Fisika (JRKPF), 4 (2), 22-28.

Fauziah, A. N., \& Kuswanto, H. (2021). The Use of Android Comics Based on Local Potentials of Embung Tambakboyo to Improve Student's Critical
Thinking Ability. In 7th International Conference on Research, Implementation, and Education of Mathematics and Sciences , 641-646.

Hidayat, N., Rostikawati, R. T., \& Marris, M. H. (2019). Pengembangan Bahan Ajar Komik Webtoon untuk Meningkatkan Hasil Belajar Biologi Siswa SMA Kelas XI. In Prosiding Seminar Nasional SIMBIOSIS, (Vol. 4), 318-324.

Lamminpää, J., Vesterinen, V. M., \& Puutio, K. (2020). Draw-AScience-Comic: exploring children's conceptions by drawing a comic about science. Research in Science \& Technological Education, 1-22.

Muliyati, D., Permana, H., Fauzi, M. R., Pratiwi, Y., Purwahida, R., Utami, I. S., et al. (2021, April). The development of online comics to explain the "nuclear reaction" topic. In AIP Conference Proceedings (Vol. 2331, No. 1, p. 030027). AIP Publishing LLC.

Ntobuono, N. E., Arbie, A., \& Amali, L. N. (2018). The development of gravity comic learning media based on Gorontalo culture. Jurnal Pendidikan IPA Indonesia, 7 (2), 246-251.

Priyadi, A. N., \& Kuswanto, H. (2020). Android physics comics to train the mathematical representation ability on momentum and impulse of senior high school students. In Journal of Physics: Conference Series (Vol. 1440, No. 1, p. 012041). IOP Publishing. 
Setiani., Dewi., Delya., Rahmawati., Dasmo - Pengembangan Media ...

Ramadhan, R. H., Ratnaningtyas, L., Kuswanto, H., \& Wardani, R. (2019, December). Analysis of physics aspects of local wisdom: Long Bumbung (Bamboo Cannon) in media development for android-based physics comics in sound wave chapter. Journal of Physics: Conference Series (Vol. 1397, No. 1, p. 012016). IOP Publishing.

Saputra, V. H., Pasha, D., \& Afriska, Y. (2020). Design of English Learning Application for Children Early Childhood. In Proceeding International Conference on Science and Engineering, 3, 661665.

Sari, F. P., Ratnaningtyas, L., Wilujeng, I., \& Kuswanto, H. (2019, June). Development of android comics media on thermodynamic experiment to map the science process skill for senior high school. In Journal of Physics: Conference Series (Vol. 1233, No. 1, p. 012052). IOP Publishing.

Siswoyo, Muliyati, D., Rahmadini, D., Purwahida, R., \& Simanjuntak, B. R. (2021, March). Educational comics to explore electromagnetic waves through the Hertz story to prove the Maxwells equation. In AIP Conference Proceedings (Vol. 2320, No. 1, p. 020039). AIP Publishing LLC.

Zaibon, S. B., Azman, F. N., \& Shiratuddin, N. (2019). Instrument for evaluating digital educational comic. International Journal of Advanced Computer Research, 9 (44), 316-324. 